Article

\title{
A Cross-Sectional Study of the Impact of Pain in Older People with Frailty: Findings from the Community Ageing Research 75+ (CARE75+) Study
}

\author{
Lesley Brown ${ }^{1, *}$, John Young ${ }^{2}$, Elizabeth Teale ${ }^{2}$, Gillian Santorelli ${ }^{1}$, \\ Andrew Clegg ${ }^{2}$ \\ 1 Bradford Teaching Hospitals NHS Foundation Trust, Duckworth Lane, \\ Bradford, BD9 6RJ, UK \\ 2 Faculty of Medicine and Health, University of Leeds, Leeds, LS2 9JT, UK \\ * Correspondence: Lesley Brown, Email: Lesley.Brown@bthft.nhs.uk.
}

\section{G Open Access}

Received: 01 February 2019 Accepted: 29 March 2019 Published: 03 April 2019

Copyright (c) 2019 by the author(s). Licensee Hapres, London, United Kingdom. This is an open access article distributed under the terms and conditions of Creative Commons Attribution 4.0 International License.

\section{ABSTRACT}

Background: Pain prevalence is higher in older people with frailty compared to fit older people. However, little is known about pain impact on the lives of older people with frailty.

Objectives: To investigate pain impact in community dwelling older people ( $\geq 75$ years) using data from the Community Ageing Research $75+$ (CARE75+) cohort study (UKCRN 18043).

Methods: Participants were assessed as not frail, pre-frail or frail (phenotype model of frailty). Pain impact was measured using the Geriatric Pain Measure Short-Form (GPM-12), an instrument incorporating 10 items on how pain impacts on ambulation, social engagement, ability to accomplish tasks and sleep, along with current pain intensity and average pain intensity (last 7 days). Intrusive pain was calculated from an item in the Short-Form 36 questionnaire. Differences in the GPM-12 scores between frailty categories were compared using Kruskal-Wallis $\mathrm{H}$ tests. Logistic regression models were used to investigate the association between frailty and intrusive pain.

Results: 887 participants: not frail 139; pre-frail 471; and frail 268. Total GPM-12 median (IQR): not-frail $5.0(0.0,12.5)$; pre-frail $10.0(0.0,27.5)$; and frail $40.0(10.0,65.0)(p \leq 0.0001)$. Current pain: not frail $0.0(0.0,1.0)$; prefrail $0(0.0,3.0)$; and frail $3.0(0.0,5.0)(p \leq 0.0001)$. Average pain: not-frail 0.0 (0.0, 2.0); pre-frail $1(0.0,4.0)$; frail $4.0(2.0,6.8)(p \leq 0.0001)$. There was a strong association between being frail and intrusive pain (adjusted for sex, ethnicity, mood and high comorbid burden): OR 3.53 (95\% CI 2.47, 5.04).

Conclusions: This research has identified an important new finding that pain in older people with frailty appears to be of sufficient severity to impact negatively on multiple aspects of day-to-day life. 
KEYWORDS: pain; frailty; older people; cohort; CARE75+

\section{BACKGROUND}

Frailty is a condition characterised by loss of biological reserves, failure of homeostatic mechanisms and vulnerability to disproportionate changes in health after relatively minor events such as changes in medication, or a minor operation or minor infection [1]. Approximately 10 percent of people over 65 years, and between 25 percent and 50 percent of people aged over 85 years are frail [1].

In the last 20 years there has been a conceptualisation of frailty as an abnormal health state in relation to the ageing process. This has resulted in the development of robust and validated models and tools to identify and severity grade frailty [2,3]. Increasingly, frailty is considered as a long-term condition requiring long-term strategies [4].

Over $40 \%$ of older people living in the community have persistent pain [5]. Cohort and cross-sectional study data indicate a higher prevalence of pain in older people with frailty and pre-frailty compared with fit older people [6]. Additionally, older people with frailty typically rate their pain as more severe, compared with fit older people, and are more likely to use analgesics [7]. There are mechanisms that might account for increased pain prevalence in older people with frailty. Physiological changes associated with frailty (brain, immune system, endocrine system and the skeletal system) [1] may alter pain perception or exacerbate pain. There is recent evidence of a genetic link between frailty and some pain conditions [8]. Additionally, mood state can impact on pain [9], and older people with frailty experience more depression than fit older people [10].

A recent systematic review that included five longitudinal studies involving 13,120 participants with mean ages of between 59 to 85 years old [11] reported that people with persistent pain at baseline had twice the risk of developing frailty during follow-up between three and eight years. This was an important finding as it suggested that interventions targeting pain might have the potential to attenuate frailty trajectories and thereby lessen disability. However, in this review [11], and an earlier review of cross-sectional studies [6], it was evident that the impact of pain on the day-to-day lives of older people with different severity grades of frailty had not been investigated as the assessment tools were predominantly single item measures to identify the presence of pain or pain severity.

We report a more comprehensive assessment of pain in older people with and without frailty, with a particular focus on pain impact using data from participants recruited to a UK multi-site community cohort study. 


\section{Aim}

The aim of this study was to investigate the impact of pain in older people with and without frailty.

\section{METHODS}

\section{Study Design}

Cross-sectional analysis of baseline data from the Community Ageing Research 75+ (CARE75+) cohort study.

\section{Setting}

CARE75+ (Trial registration number ISRCTN16588124) is a UK longitudinal study across 28 sites investigating health and socioeconomic circumstances, with a focus on frailty status and frailty trajectories and funded by the National Institute for Health Research (NIHR) Collaboration for Leadership in Applied Health Research and Care Yorkshire and Humber (CLAHRC YH). Ethics approval for CARE75+ was provided by National Research Ethics Service Committee, Yorkshire \& the Humber-Bradford \& Leeds, October 10th, 2014 (14/YH/1120).

\section{Participants}

Community-dwelling older people aged 75 years and over are recruited to CARE75+ via general practices. Potential participants are sent brief study information from their general practice and requested to inform the practice if they want to 'opt out' of being contacted by a researcher. Those who have not opted out are then contacted by a researcher by telephone to arrange a home visit to discuss the study in more detail [12]. This method has resulted in an approximate $40 \%$ participation rate [12]. Care home residents and people living at home who were bedbound, people with terminal cancer, those in receipt of the Amber Care Bundle (estimated life expectancy of three months or fewer), and people in receipt of palliative care services were excluded. Participants gave informed full written consent, or consultee assent was obtained if capacity to give consent was impaired.

The present study is a cross-sectional analysis of baseline data from 887 CARE75+ participants recruited between January 2015 and November 2018.

\section{Variables}

All variables were collected during face-to-face visits by researchers in the participant's home.

\section{Frailty}

We used the phenotype model to define frailty for this study [2]. 
1 Walking speed was assessed by a timed three metre walk and results stratified by height and gender using values described in the original Cardiovascular Health Study, from which the phenotype model was derived.

2 Weight loss was determined by the following question. "In the last year, have you lost more than 10 lbs unintentionally?”

3 Exhaustion was identified using the following question: "How often in the last week did you feel that everything you did was an effort?", and "could not get going”. Responses were: rarely or none of the time $(<1$ day) $=0$; some or a little of the time (1-2 days) $=1$; moderate amount of the time (3-4 days) $=2$; most of the time $=3$. If the participant answered " 2 " or " 3 " to either question they met the criterion for exhaustion.

4 Grip strength was assessed using a Jamar dynamometer and stratified using criteria from the Cardiovascular Health Study [2].

5 Low activity was assessed using data obtained from the Physical Activity section of the SF36 [13,14] which includes ten items on physical activity with responses of: Yes, limited a lot $=0$; Yes, limited a little $=50$; and No, not limited at all $=100$. Scores are calculated and divided by 10 . Men are considered to have low physical activity with a score of $\leq 75$ and women $\leq 60$.

Participants were considered frail if they had three or more of the frailty criteria, pre-frail with one or two criteria and not frail if none of the criteria were met.

\section{Pain}

The Geriatric Pain Measure Short Form (GPM-12): The GPM-12 is a validated measure for assessing pain in older adults [15]. It provides a multi-dimensional pain assessment incorporating 10 items on how pain impacts on ambulation, social engagement, ability to accomplish tasks and on sleep, along with current pain intensity (pain today) (0-10 scale, with higher scores indicating greater pain) and average pain intensity in the last 7 days (0-10 scale, with higher scores indicating greater pain). An overall total score is calculated by summing the items, and transformation to a 0-100 scale, with higher scores demonstrating overall greater pain impact.

Intrusive pain: We defined intrusive pain by dichotomising responses to the following question from the SF-36 [13] "During the past 4 weeks, how much did pain interfere with your normal work (including both work outside the home and housework)?”. Options were not at all; a little bit; moderately; quite a bit; extremely. Those who gave a response of 'moderately/quite a bit/extremely' were defined as having intrusive pain [16]. 


\section{Confounders and other variables}

Low mood was assessed using the Geriatric Depression Scale Short-Form (GDS-SF) [17], with a score of $\geq 5$ indicating an abnormal low mood state. The following were obtained from the primary care clinical records:

- Analgesic medication classified as: non-opioid analgesic and compound preparations; opioid analgesics; neuropathic pain preparations (e.g., capsaicin \& gabapentin); and non-steroidal anti-Inflammatory drugs (NSAIDs).

- A history of osteoarthritis or rheumatoid arthritis.

- The number of comorbid conditions, with a high comorbid burden defined as the presence of four or more conditions identified from the primary care clinical record, consistent with previous research [16].

\section{Statistical Analysis}

Participant characteristics are presented as frequencies (\%), means with standard deviation (SD) and range and medians with Inter Quartile Range (IQR). Data were tested for normality using Kolmogorov-Smirnov and Shapiro-Wilk tests. Differences in characteristics among categories of frailty states (fit, pre-frail, frail) were compared by Chi-squared or Fisher Exact tests and Kruskal-Wallis $H$ tests for non-parametric continuous variables for the pain impact assessment.

Logistic regression was used to investigate the relationship between frailty (independent variable) and intrusive pain (dichotomised dependent variable), with frail participants compared to pre-frail or not frail participants. The regression model was adjusted for sex, ethnicity (white/not white), depressed mood (GDS-SF $\geq 5$ ) and a high comorbid burden. Data analysis was performed using Statistical Package for the Social Sciences (SPSS) Version 21 software [18]. A complete case analysis was planned if missing data was less than $10 \%$ for all variables. Multiple imputation was planned if missing data was $>10 \%$ for any variable.

\section{RESULTS}

Data from 887 CARE75+ participants is included in the analysis. Nine participants (1\%) did not have frailty assessment results. Missing data was less than $10 \%$ for the other variables. Table 1 shows the characteristics of the CARE75+ cohort as a whole and by frailty status.

\section{GPM-12}

There were significant differences in individual items on the GPM-12 (Table 2). There were statistically significant differences in total GPM-12 score, GPM-12 current pain intensity and GPM-12 average pain intensity, with higher scores observed in participants with frailty compared to those who were not frail or pre-frail (Table 2). 


\section{Intrusive Pain}

Being frail compared with being pre-frail or not frail was associated with a greater odds of experiencing intrusive pain (adjusted Odds Ratio 3.53 (95\% Confidence Interval 2.47 to 5.04 ).

Table 1. The characteristics of the study population.

\begin{tabular}{|c|c|c|c|c|}
\hline Characteristic & $\begin{array}{l}\text { All } \\
n=887\end{array}$ & $\begin{array}{c}\text { Not-frail } \\
139(15.7 \%)\end{array}$ & $\begin{array}{c}\text { Pre-frail } \\
471(53.1 \%)\end{array}$ & $\begin{array}{c}\text { Frail } \\
268(30.2 \%)\end{array}$ \\
\hline $\begin{array}{l}\text { Age (years) mean (standard deviation), } \\
\text { range }\end{array}$ & $\begin{array}{l}81.5(4.9) \\
75-99\end{array}$ & $79.1(3.5)$ & $80.9(4.5)$ & $83.6(5.4)$ \\
\hline Female & $464(52.3)$ & $58(41.7)$ & $237(50.3)$ & $162(60.4)$ \\
\hline \multicolumn{5}{|l|}{ Ethnicity } \\
\hline White & $825(93.0)$ & $135(97.1)$ & $447(94.9)$ & $235(87.7)$ \\
\hline South Asian (Pakistani or Bangladeshi) & $58(6.5)$ & $4(2.9)$ & $23(4.9)$ & $31(11.6)$ \\
\hline Other & $4(0.5)$ & $0(0)$ & $1(0.2)$ & $2(0.7)$ \\
\hline \multicolumn{5}{|l|}{ Frailty status } \\
\hline Not frail & $139(15.7)$ & - & - & - \\
\hline Pre-frail & $471(53.1)$ & - & - & - \\
\hline Frail & $268(30.5)$ & - & - & - \\
\hline $\begin{array}{l}\text { GPM-12 Current pain (0-10 scale), } \\
\text { median (IQR) }\end{array}$ & $1.0(0.0,4.0)$ & $0(0.0,1.0)$ & $0(0,3.0)$ & $3.0(0,5.0)$ \\
\hline $\begin{array}{l}\text { GPM-12 Average pain (last } 7 \text { days) } \\
\text { (0-10 scale), median (IQR) }\end{array}$ & $2.0(0.0,5.0)$ & $0(0.0,2.0)$ & $1(0.0,4.0)$ & $4.0(2.0,6.8)$ \\
\hline $\begin{array}{l}\text { GPM-12 Total score (0-100 scale), } \\
\text { median (IQR) }\end{array}$ & $12.5(0.0,42.5)$ & $5.0(0.0,12.5)$ & $10.0(0.0,27.5)$ & $40.0(10.0,65.0)$ \\
\hline Intrusive pain (SF-36) & $219(24.7)$ & $9(6.5)$ & $84(17.9)$ & $126(47.2)$ \\
\hline $\begin{array}{l}\text { Osteoarthritis (Primary care health } \\
\text { record) }\end{array}$ & $316(35.6)$ & $28(21.2)$ & $153(35.2)$ & $133(54.3)$ \\
\hline $\begin{array}{l}\text { Rheumatoid arthritis (Primary care } \\
\text { health record) }\end{array}$ & $25(2.8)$ & $1(0.8)$ & $12(2.7)$ & $12(4.9)$ \\
\hline $\begin{array}{l}\text { High comorbid burden (Primary care } \\
\text { health record) }\end{array}$ & $447(50.4)$ & $50(36.0)$ & $224(47.6)$ & $167(62.3)$ \\
\hline Depressed mood (GDS-SF $\geq 5$ ) & $135(15.2)$ & $1(0.7)$ & $41(8.8)$ & $91(34.0)$ \\
\hline \multicolumn{5}{|l|}{ Prescribed analgesic medication } \\
\hline $\begin{array}{l}\text { Non-opioid analgesic and compound } \\
\text { preparations }\end{array}$ & $191(21.5)$ & $15(10.8)$ & $80(17.0)$ & $95(35.4)$ \\
\hline Opioid analgesics & $37(4.2)$ & $0(0.0)$ & $12(2.5)$ & $25(9.3)$ \\
\hline Neuropathic pain medication & $23(2.6)$ & $1(0.7)$ & $10(2.1)$ & $12(4.5)$ \\
\hline $\begin{array}{l}\text { Non-Steroidal Anti-Inflammatory } \\
\text { drugs }\end{array}$ & $64(7.2)$ & $8(5.8)$ & $31(6.6)$ & $25(9.3)$ \\
\hline
\end{tabular}

Values are $n$ (\%) unless otherwise stated. GPM-12, The Geriatric Pain Measure Short Form; SF-36, RAND Short-Form 36-Item Health Survey; GDS-SF, Geriatric Depression Scale Short-Form; IQR, Inter Quartile Range. 
Table 2. The Geriatric Pain Measure Short-Form by frailty status.

\begin{tabular}{|c|c|c|c|c|}
\hline Individual items and total score & $\begin{array}{c}\text { Fit } \\
n(\%)\end{array}$ & $\begin{array}{l}\text { Pre-frail } \\
n(\%)\end{array}$ & $\begin{array}{l}\text { Frail } \\
n(\%)\end{array}$ & $p$ value \\
\hline $\begin{array}{l}\text { Do you currently have pain with or have you } \\
\text { stopped moderate activities such as moving a } \\
\text { heavy table, pushing a vacuum cleaner, bowling, } \\
\text { or playing golf because of pain? }\end{array}$ & $10(7.2)$ & $109(23.3)$ & $135(51.5)$ & $<0.001^{\mathrm{a}}$ \\
\hline $\begin{array}{l}\text { Do you currently have pain with or have you } \\
\text { stopped climbing more than one flight of stairs } \\
\text { because of pain? }\end{array}$ & $5(3.6)$ & $79(17.0)$ & $115(44.4)$ & $<0.001^{\mathrm{a}}$ \\
\hline $\begin{array}{l}\text { Do you currently have pain with or have you } \\
\text { stopped walking more than } 200 \text { yards because of } \\
\text { pain? }\end{array}$ & $3(2.2)$ & $68(14.6)$ & $124(47.0)$ & $<0.001^{\mathrm{a}}$ \\
\hline $\begin{array}{l}\text { Do you currently have pain with or have you } \\
\text { stopped walking } 200 \text { yards or less because of pain? }\end{array}$ & $2(1.4)$ & $43(9.2)$ & $103(39.2)$ & $<0.001^{\mathrm{a}}$ \\
\hline $\begin{array}{l}\text { Because of pain, have you cut down the amount of } \\
\text { time you spend on work or other activities? }\end{array}$ & $9(6.5)$ & $86(18.3)$ & $114(43.3)$ & $<0.001^{\mathrm{a}}$ \\
\hline $\begin{array}{l}\text { Because of pain, have you been accomplishing less } \\
\text { than you would like to? }\end{array}$ & $14(10.1)$ & $107(22.8)$ & $142(53.6)$ & $<0.001^{\mathrm{a}}$ \\
\hline $\begin{array}{l}\text { Because of pain, have you limited the kind of work } \\
\text { or other activities you do? }\end{array}$ & $16(11.5)$ & $115(24.5)$ & $147(55.5)$ & $<0.001^{\mathrm{a}}$ \\
\hline $\begin{array}{l}\text { Because of pain, does the work or activities you do } \\
\text { require extra effort? }\end{array}$ & $14(10.1)$ & $120(25.7)$ & $147(55.5)$ & $<0.001$ \\
\hline Because of pain, do you have trouble sleeping? & $6(4.3)$ & $70(15.0)$ & $80(30.0)$ & $<0.001$ \\
\hline $\begin{array}{l}\text { Does pain prevent you from enjoying any other } \\
\text { social or recreational activities (other than } \\
\text { religious services)? }\end{array}$ & $9(6.5)$ & $54(11.5)$ & $92(34.6)$ & $<0.001^{\mathrm{a}}$ \\
\hline GPM-12 Current pain (0-10) (median IQR) & $0(0.0,1.0)$ & $0(0,3.0)$ & $3.0(0,5.0)$ & $<0.001^{\mathrm{b}}$ \\
\hline $\begin{array}{l}\text { GPM-12 Average pain (0-10) (last } 7 \text { days) (median } \\
\text { IQR) }\end{array}$ & $0(0.0,2.0)$ & $1(0.0,4.0)$ & $4.0(2.0,6.8)$ & $<0.0001^{\mathrm{b}}$ \\
\hline GPM-12 Total score (0-100) (median IQR) & $5.0(0.0,12.5)$ & $10.0(0.0,27.5)$ & $40.0(10.0,65.0)$ & $<0.001^{\mathrm{b}}$ \\
\hline
\end{tabular}

Note: counts are for 'yes' responses; Chi-squared tests ( $\chi^{2}$ tests); ${ }^{\text {a }} \quad$ Fisher Exact tests (Cells have expected counts less than 5$) ;{ }^{\mathrm{b}}$ Kruskal-Wallis $H$ tests.

\section{DISCUSSION}

The study has identified that there is a higher overall burden of pain in older people with frailty compared to older people without frailty, a finding that is consistent with our earlier systematic review and other recent evidence. However, the research has identified an important new finding that pain in older people with frailty appears to be of sufficient severity to impact negatively on multiple aspects of day-to-day life. There were statistically significant differences in scores in older people with frailty on the GPM-12 instrument to indicate pain is impacting on their mobility, their ability to participate in recreational activities, their ability to 
accomplish everyday tasks, and on their sleep. These are key aspects of daily life and it is not unreasonable to assume, therefore, that quality of life is adversely affected. It would be important to confirm this in future studies.

This higher burden of pain experienced by older people with frailty may contribute to further decline as the person is at risk of becoming more isolated through an inability to participate socially, and further dependent on others to accomplish daily tasks. Our unadjusted data suggest potentially low mood in those with frailty compared to older people without frailty. Whilst beyond the scope of this particular analysis, this would be consistent with a previous cross-sectional analysis of pain and depression in older people [19]. Pain and low mood are inextricably linked: pain is both an antecedent and a consequence of depression [9], and avoidance and withdrawal are commonly observed in both pain and depressed populations. Additionally, it has been proposed that when a person perceives pain as threatening, they typically respond with avoidance behaviours which can contribute to a decrease in functioning which may result in disability [20]. The pain experienced by older people with frailty in this study reduced their ability to accomplish tasks and participate in leisure activities. However, there is the potential that low mood may contribute to a lack of motivation for participating in activities leading to a more sedentary lifestyle and associated increased pain, thus perpetuating a negative cycle.

Older people with frailty are core users of health services, including primary care services [21], but qualitative evidence suggests that pain is often not prioritised during routine consultations, which may focus on the other health conditions that exist in the context of frailty [22]. Furthermore, there may be a reluctance to take pain medication on top of medication for other conditions [22]. In this study, approximately $25 \%$ of older adults experienced intrusive pain, and over $40 \%$ of older people with frailty, suggesting that a considerable proportion of older people experience pain that is sub-optimally controlled.

Pharmacological management of pain in older people with frailty has inherent challenges as frailty may be predictive of an individual's pharmo-kinetic and pharmacodynamic response to medication, so medication changes can disproportionately and negatively impact on an older person with frailty [1]. This can manifest with less predictable responses, increased drug sensitivity and a greater potential for harmful side effects [23]. Guidance on the management of pain in older people with frailty suggests paracetamol should be the initial pharmacological treatment option. Non-steroidal anti-inflammatory drugs should be used with caution in older people after safer treatments have been tried [24]. Older people with frailty in this study were more likely to be in receipt of opioids for pain compared to fit older people, in line with previous findings in a well-characterised cohort of older people [7]. There have been concerns regarding opioid use in older people [25] and a paucity of quality evidence for their use in populations with frailty [23]. Consistent with these concerns, available guidelines recommend opioid use should 
only be considered when older people experience moderate or severe pain [24].

Poorly managed pain is associated with impaired activities of daily living, decreased ambulation and cognitive impairment [26], with recent evidence suggesting worsening frailty and increase in incident frailty [11]. A meta-analysis of cross-sectional study data identified a strong association between pain related fear and disability [27], but inferences about the direction of the relationship could not be made. However, as frailty is often present with disability and co-morbidity, and the overlap increases with greater frailty [28], there is the potential for a perpetuating cycle of pain, and immobility with further worsening frailty.

Current UK health policy [29] has highlighted the need to develop proactive services for older people with frailty. Furthermore, the 2017/18 UK General Medical Services primary care contract incorporates a contractual requirement to undertake a clinical review for people living with frailty, including provision of appropriate treatment. We recommend that proactive services for older people living with frailty should consider inclusion of appropriate measures to enquire about and address intrusive pain that is impacting on day-to-day life.

\section{Strengths of the Study}

This study used data from a well-characterised cohort of older people with and without frailty identified using the well-validated phenotype model. The recruitment rate of approximately $40 \%$ is comparable to other UK cohorts recruiting similar populations [30]. The study has broad inclusion criteria, with few exclusions, therefore we are confident that results are broadly generalisable to the wider community dwelling older population.

We were able to adjust for important confounders, including ethnicity. This is an important variable which may account for differences in pain sensitivity, pain reporting and coping strategies [31,32]. The GPM-12 provided a comprehensive measure of pain and pain impact and we have included a robust, validated measure of intrusive pain. There was minimal missing data on the important variables of frailty, intrusive pain and the GPM-12, thus providing confidence in the results of this analysis.

\section{Limitations of the Study}

The study was limited to an analysis of cross-sectional data, so we were unable to investigate pain severity, impact on activities, and frailty trajectories over time. Our intention is to undertake longitudinal analysis when we have sufficient data at follow-up time-points. Previous studies have investigated frailty trajectories based on a baseline pain assessment. In a male only cohort, people with chronic widespread pain at baseline had worsened frailty at final follow up (average 4.3 years) [33]; and similarly in a mixed cohort from the English Longitudinal Study of Ageing (ELSA), pain was associated with an increased risk and intensity of frailty [34]. This would suggest that pain is potentially an important precursor to frailty. 
Although we collected information on osteoarthritis and rheumatoid arthritis, a detailed description of individual pain syndromes and potential causative factors of pain in participants was beyond the scope of this study. In our previous systematic review [6] of pain in older people with frailty, one study specifically recruited older people with musculoskeletal pain [7] and one study limited inclusion to older people with osteoarthritis of the knee and hip [35]. Epidemiological evidence suggests osteoarthritis and rheumatoid arthritis combined are the most common cause of pain, including in the UK [36]. Within this analysis, those with frailty appeared more likely to have a GP diagnosis of osteoarthritis compared to their less frail counterparts. Additionally, those with frailty reported more pain in the previous 7 days. There is the potential that conditions, such as arthritis lead to pain and therefore reduced mobility, resulting in frailty. We intend to investigate this within the CARE75+ cohort.

Finally, results from analysis of the GPM-12 were limited to unadjusted analysis, with low numbers in some groups, which precluded pair wise comparisons and further scrutiny between the sub-categories of the different frailty states.

\section{CONCLUSIONS}

We report new evidence that pain in older people with frailty is particularly intrusive and of a severity which appears to impact negatively on day-to-day life. We recommend that clinicians enquire about pain during routine encounters with older people with frailty. Future epidemiological research to investigate the longitudinal impact of pain on frailty, disability and quality of life, and qualitative research to explore individual experiences and coping strategies will help inform development and targeting of pain management interventions to increase independence and reduce service demand for this vulnerable group.

\section{AVAILABILITY OF DATA AND MATERIAL}

The datasets used and analysed during the current study are available from the corresponding author on reasonable request.

\section{FUNDING}

This research was funded by the National Institute for Health Research (NIHR), Collaboration for Leadership in Applied Health Research and Care Yorkshire and Humber (NIHR CLAHRC YH). www.clahrc-yh.nihr.ac.uk (NIHR CLAHRC Yorkshire and Humber IS-CLA0113-10020). The views and opinions expressed are those of the author(s), and not necessarily those of the NIHR or the Department of Health and Social Care. 


\section{AUTHOR CONTRIBUTIONS}

LB, AC, ET, JY and GS provided substantial contributions to the design of the work and analysis and interpretation of data and revising it for critically important intellectual content. All authors read and approved the final manuscript.

\section{ACKNOWLEDGEMENTS}

We are grateful to the National Institute for Health Research Clinical Research Networks (NIHR CRNs) in North East \& North Cumbria; South West Peninsula; West Midlands; and Yorkshire \& Humber, along with participating general practices for their support in recruiting participants to the CARE75+ study.

We are also grateful for the substantial contributions by lay members of the CARE75+ Frailty Oversight Group who helped finalise the CARE75+ protocol, test the assessment procedures and review study materials.

\section{CONFLICTS OF INTEREST}

The authors declare they have no conflicts of interest.

\section{REFERENCES}

1. Clegg A, Young J, Iliffe S, Rikkert MO, Rockwood K. Frailty in elderly people. Lancet. 2013;381(9868):752-62. doi: 10.1016/S0140-6736(12)62167-9

2. Fried LP, Tangen CM, Walston J, Newman AB, Hirsch C, Gottdiener J, et al. Frailty in older adults evidence for a phenotype. J Gerontol A. 2001;56(3):M146-57.

3. Rockwood K, Song X, MacKnight C, Bergman H, Hogan DB, McDowell I, et al. A global clinical measure of fitness and frailty in elderly people. CMAJ. 2005;173(5):489-95.

4. Harrison JK, Clegg A, Conroy SP, Young J. Managing frailty as a long-term condition. Age Ageing. 2015;44(5):732-5. doi: 10.1093/ageing/afv085

5. Maxwell CJ, Dalby DM, Slater M, Patten SB, Hogan DB, Eliasziw M, et al. The prevalence and management of current daily pain among older home care clients. Pain. 2008;138(1):208-16. doi: 10.1016/j.pain.2008.04.007

6. Brown L, Young J, Clegg A, Heaven A. Pain in older people with frailty. Rev Clin Gerontol. 2015;25(3):159-71.

7. Koponen MP, Bell JS, Karttunen NM, Nykanen IA, Desplenter FA, Hartikainen SA. Analgesic use and frailty among community-dwelling older people: a population-based study. Drugs Aging. 2013;30(2):129-36. doi: 10.1007/s40266-012-0046-8

8. Livshits G, Ni Lochlainn M, Malkin I, Bowyer R, Verdi S, Steves CJ, et al. Shared genetic influence on frailty and chronic widespread pain: a study from TwinsUK. Age Ageing. 2018;47(1):119-25. doi: 10.1093/ageing/afx122

9. Goesling J, Clauw DJ, Hassett AL. Pain and Depression: An Integrative Review of Neurobiological and Psychological Factors. Curr Psychiatry Rep. 2013;15(12):1-8. doi: 10.1007/s11920-013-0421-0 
10. Mezuk B, Edwards L, Lohman M, Choi M, Lapane K. Depression and frailty in later life: a synthetic review. Int J Geriatr Psychiatry. 2012;27(9):879-92. doi: 10.1002/gps.2807

11. Saraiva MD, Suzuki GS, Lin SM, de Andrade DC, Jacob-Filho W, Suemoto CK. Persistent pain is a risk factor for frailty: a systematic review and metaanalysis from prospective longitudinal studies. Age Ageing. 2018;47(6): 785-93. doi: 10.1093/ageing/afy104

12. Heaven A, Brown L, Young J, Teale E, Hawkins R, Spilsbury K, et al. The Community Ageing Research 75+ Study (CARE75+): an experimental ageing and frailty research cohort. BMJ Open. 2019;9(3):e026744. doi: 10.1136/bmjopen-2018-026744

13. Hays RD, Sherbourne CD, Mazel RM. The rand 36 item health survey 1.0. Health Econ. 1993;2(3):217-27.

14. Theou O, Cann L, Blodgett J, Wallace LM, Brothers TD, Rockwood K. Modifications to the frailty phenotype criteria: Systematic review of the current literature and investigation of 262 frailty phenotypes in the Survey of Health, Ageing, and Retirement in Europe. Ageing Res Rev. 2015;21:78-94. doi: 10.1016/j.arr.2015.04.001

15. Blozik E, Stuck AE, Niemann S, Ferrell BA, Harari D, von Renteln-Kruse W, et al. Geriatric Pain Measure short form: development and initial evaluation. J Am Geriatr Soc. 2007;55(12):2045-50.

16. Blyth FM, Rochat S, Cumming RG, Creasey H, Handelsman DJ, Couteur DGL, et al. Pain, frailty and comorbidity on older men: The CHAMP study. Pain. 2008;140(1):224-30. doi: 10.1016/j.pain.2008.08.011

17. Yesavage JA, Sheikh JI. 9/Geriatric depression scale (GDS) recent evidence and development of a shorter version. Clin Gerontol. 1986;5(1-2):165-73.

18. IBM Corporation. IBM SPSS Statistics for Windows. Version 22.0. Armonk: IBM Corporation; 2013.

19. Lin CC, Li CI, Chang CK, Liu CS, Lin CH, Meng NH, et al. Reduced healthrelated quality of life in elders with frailty: a cross-sectional study of community-dwelling elders in Taiwan. PLoS One. 2011;6(7):e21841. doi: 10.1371/journal.pone.0021841

20. Vlaeyen JW, Linton SJ. Fear-avoidance and its consequences in chronic musculoskeletal pain: a state of the art. Pain. 2000;85(3):317-32

21. Oliver D, Foot C, Humphries R. Making our health and care systems fit for an ageing population. London, UK: The King's Fund; 2014. Available from: https://www.kingsfund.org.uk/sites/default/files/field/field publication file/ making-health-care-systems-fit-ageing-population-oliver-foot-humphriesmar14.pdf. Accessed 2019 Mar 19.

22. Davis GC, Hiemenz ML, White TL. Barriers to managing chronic pain of older adults with arthritis. J Nurs Scholarsh. 2002;34(2):121-26.

23. van Ojik AL, Jansen PA, Brouwers JR, van Roon EN. Treatment of chronic pain in older people. Drugs Aging. 2012;29(8):615-25. doi: 10.2165/11632620000000000-00000 
24. Abdulla A, Adams N, Bone M, Elliott AM, Gaffin J, Jones D, et al. Guidance on the management of pain in older people. Age Ageing. 2013;42(Suppl 1):i1-57. doi: 10.1093/ageing/afs200

25. Smith H, Bruckenthal P. Implications of opioid analgesia for medically complicated patients. Drugs Aging. 2010;27(5):417-33. doi: 10.2165/11536540000000000-00000

26. Rastogi R, Meek BD. Management of chronic pain in elderly, frail patients: finding a suitable, personalized method of control. Clin Interv Aging. 2013;8:37. doi: 10.2147/CIA.S30165

27. Zale EL, Lange KL, Fields SA, Ditre JW. The relation between pain-related fear and disability: a meta-analysis. J Pain. 2013;14(10):1019-30. doi: 10.1016/j.jpain.2013.05.005

28. Theou O, Rockwood MR, Mitnitski A, Rockwood K. Disability and comorbidity in relation to frailty: how much do they overlap? Arch Gerontol Geriatr. 2012;55(2):e1-8. doi: 10.1016/j.archger.2012.03.001

29. NHS Five Year Foreword View. Available from: https://www.england.nhs.uk/wp-content/uploads/2014/10/5yfv-web.pdf. Accessed 2019 Mar 19.

30. Clegg A, Relton C, Young J, Witham M. Improving recruitment of older people to clinical trials: use of the cohort multiple randomised controlled trial design. Age Ageing. 2015;44(4):547-50. doi: 10.1093/ageing/afv044

31. Campbell CM, Edwards RR, Fillingim RB. Ethnic differences in responses to multiple experimental pain stimuli. Pain. 2005;113(1-2):20-6.

32. Nayak S, Shiflett SC, Eshun S, Levine FM. Culture and gender effects in pain beliefs and the prediction of pain tolerance. Cross Cult Res. 2000;34(2): 135-51.

33. Wade KF, Lee DM, McBeth J, Ravindrarajah R, Gielen E, Pye SR, et al. Chronic widespread pain is associated with worsening frailty in European men. Age Ageing. 2015;45(2):268-74. doi: 10.1093/ageing/afv170

34. Wade KF, Marshall A, Vanhoutte B, Wu FC, O'Neill TW, Lee DM. Does Pain Predict Frailty in Older Men and Women? Findings From the English Longitudinal Study of Ageing (ELSA). J Gerontol A. 2017;72(3):403-9. doi: 10.1093/gerona/glw226

35. Miguel RC, Dias RC, Dias JM, daSilva SL, Menicucci Filho PR, Ribeiro TM. Frailty syndrome in the community-dwelling elderly with osteoarthritis. Rev Bras Reumatol. 2012;52(3):339-47.

36. Breivik H, Collett B, Ventafridda V, Cohen R, Gallacher D. Survey of chronic pain in Europe: prevalence, impact on daily life, and treatment. Eur J Pain. 2006;10(4):287-333.

How to cite this article:

Brown L, Young J, Teale E, Santorelli G. Clegg A. A Cross-Sectional Study of the Impact of Pain in Older People with Frailty: Findings from the Community Ageing Research 75+ (CARE75+) Study. Adv Geriatr Med Res. 2019;1:e190002. https://doi.org/10.20900/agmr20190002 